\title{
Electrochemical Oxidation Mechanism of Photochromic Switches: Electrodimerisation, Ring Closure or Ring Opening?
}

\author{
Christophe Coudret,,${ }^{a}$, Iluminada Gallardo,,${ }^{\text {, * }}$ Gonzalo Guirado,, ,** \\ Jean-Pierre Launay ${ }^{a, *}$ \\ ${ }^{a}$ NanoSciences Group, CEMES-CNRS, 29 rue Jeanne Marvig, BP 94347, \\ F-31055 Toulouse Cedex 4, France \\ ${ }^{b}$ Departament de Química, Universitat Autònoma de Barcelona \\ 08193-Bellaterra (Barcelona), Spain
}

\begin{abstract}
Simple photochromic dithienylethylenes with either perfluoro or perhydro cyclopentene ring, and a variety of substituents have been prepared and their electrochemical behavior explored by cyclic voltammetry. All present two electron irreversible oxidation waves in their open form, but the radical cation of the open isomers can follow three different reaction pathways: dimerisation, ring closure, or ring reopening. Whereas the chloro derivative follows a dimerisation mechanism $\left(\mathrm{EC}_{2} \mathrm{E}\right.$ mechanism), the phenylthio substituted compound displays an efficient oxidative ring closure (ECE or DISP1 mechanism). Interesting electrochromic behavior is associated with this compound, a redox process occurring in the range $0.5-1.5 \mathrm{~V}$ is observed by monitoring the absorption species changes (colored species) in function of the applied potential. Furthermore, electrochromic properties are also found in the corresponding ring closed isomers. Depending on the substituents on the thiophene ring and the perfluro or perhydro cyclopentene ring, open isomers can be obtained from oxidation (chemical or electrochemical) of the corresponding ring closed isomers via EC mechanism. These observations should be taken into account for the potential design of three-state conjugated systems and photoelectrical molecular switching.
\end{abstract}

Keywords: diethienylethylenes, cyclic voltammetry, electrochemical oxidation mechanism, molecular switches, isomerization kinetics.

\section{Introduction}

The design of molecular switching devices requires single molecular units which can be reversibly triggered by applying external stimuli such as light, heat or

\footnotetext{
* Corresponding authors. E-mail addresses: coudret@cemes.fr, launay@cemes.fr, Iluminada.Gallardo@uab.es, Gonzalo.Guirado@uab.es
} 
electricity [1]. A molecule which can undergo different types of transformation depending on the type of the external stimulus may be used as a molecular device for multiple-mode information processing [2]. In this sense, much effort has been focused on the study of optical memory systems which respond to electrical inputs [3]. Photochromic dithienylethene derivatives have hence attracted the attention since they present two isomeric forms, one of these being of a polyene type thus more "transparent to electrons", [4] that could be interconverted by light-induced electrocyclic reactions. However, such reactions are expected to be sensitive to oxidation and various pericyclic reactions are accelerated when radical cations are involved as intermediates. [5] For the dithienylethene family, recent reports indicate that ring-closure or -opening could be induced by oxidation [6]. Photochromic dithienylethene derivatives have hence attracted the attention since they present two isomeric forms, one of these being of a polyene type, thus more "transparent to electrons", that could be interconverted by lightinduced electrocyclic reactions.

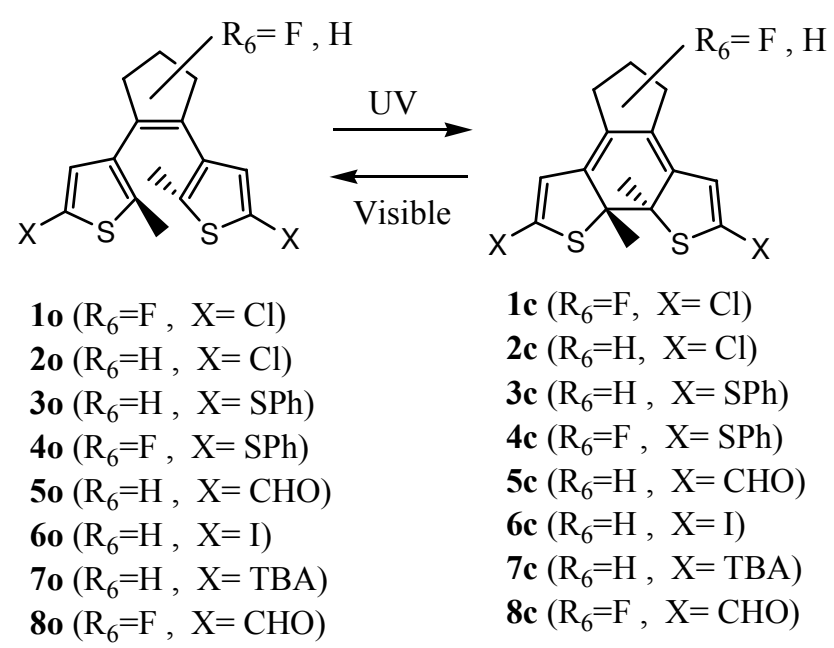

Scheme 1

The high thermal stability of both isomers [ring open (colorless isomer) and ring closed (colored isomer)] and the fatigue resistance make these type of compounds ideal candidates for optical memory devices and switching applications [4]. However, there are only a few studies of the photoelectrochromic behavior associated with the photochromic ring closure or ring opening processes in these dithienylethene derivatives [6]. In order to study the possible use of dithienylcyclopentenes derivatives as optically-electrically controllable molecular switches, the electrochemical behavior of several photochromic dithienylcyclopentenes derivatives in acetonitrile (ACN) solutions have been studied. The spectroelectrochemical changes accompanying the redox reactions, the influence of the applied potential and the charge involved in these processes have been also studied. In order to address systematically the problem, we have focused our attention on the redox behaviour of variously substituted dithienylethenes. We wish to report our results on simple compounds (scheme 1) used as model compounds to elucidate the electrochemical oxidation mechanism, and thus allow the design of optically-electrically controllable devices. 


\section{Experimental Section}

Chemicals

Dichloro compounds 10 / 20 were prepared following literature procedure [7]. The introduction of other substituents were efficiently achieved by trapping the lithiated dithienylethylene generated from $10 / 20\left({ }^{\mathrm{t}} \mathrm{BuLi}-78{ }^{\circ} \mathrm{C}\right.$ ) with the corresponding electrophiles (Scheme 2). Isomerisation to the closed isomers was performed photochemically. Irradiation of the samples was performed until the detection of degradation products. ${ }^{1} \mathrm{H}$ NMR and cyclic voltammetry were used to determine the amounts of the two photoisomers.

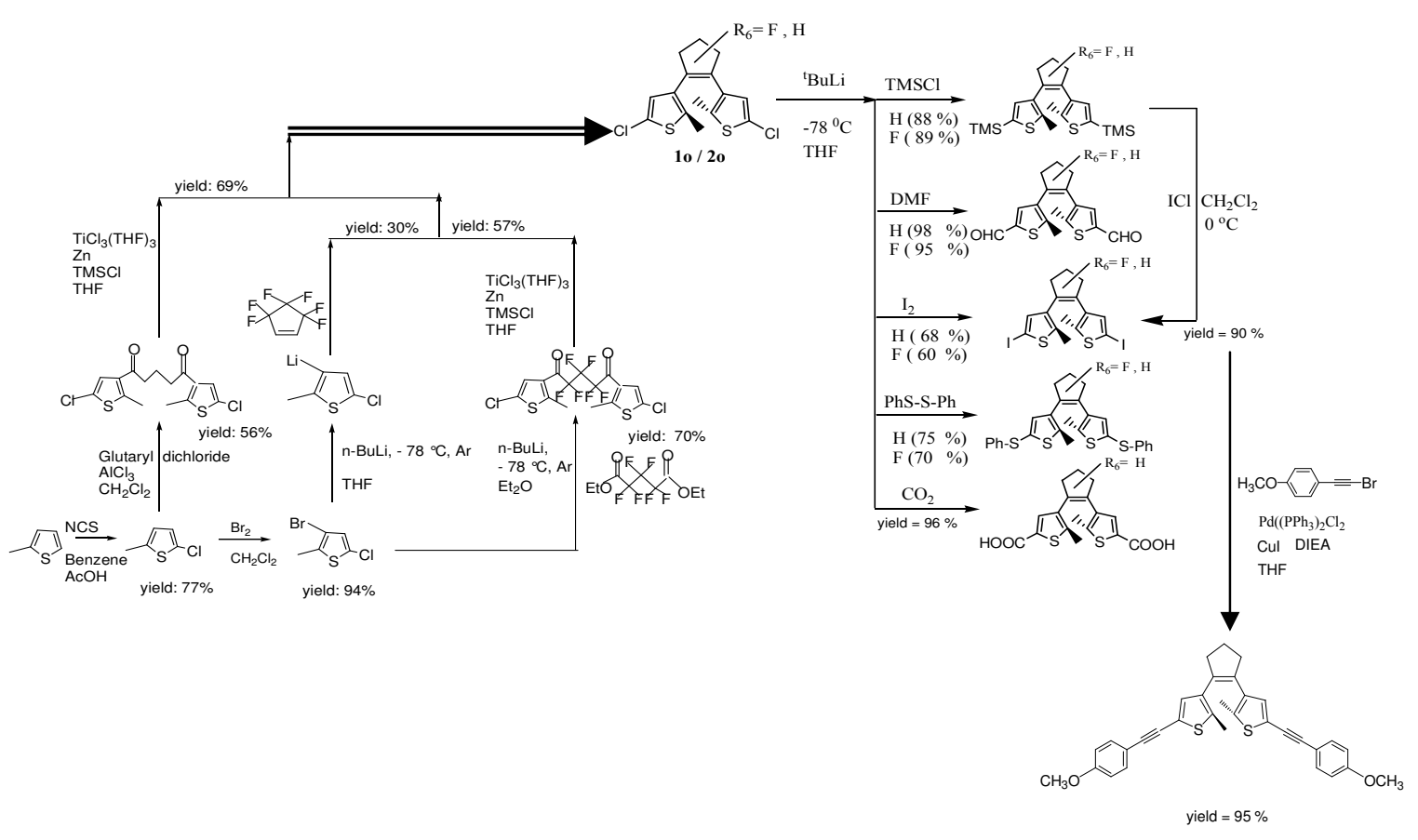

Scheme 2

\section{Electrochemical instrumentation}

Electrochemical techniques were performed with an AUTOLAB PC-controlled potentiostat. Cyclic voltammetry experiments were performed using either a glassy carbon $0.5 \mathrm{~mm}$ diameter or a platinum $1.0 \mathrm{~mm}$ diameter disk working electrode, a platinum wire counter electrode, a Saturated Calomel Electrode (SCE) isolated from the solution by a double frit system and tetrabutylammonium hexafluorophosphate $(0.1 \mathrm{M})$ as supporting electrolyte. Differential pulse voltammetry was performed with a Metrohm rotating platinum electrode (1000 rev/min) with pulses of $70 \mathrm{~ms}$ duration and $25 \mathrm{mV}$ amplitude.

Potential controlled electrolysis experiments were performed using a platinum grid as a working electrode. The applied potential was c.a. $100 \mathrm{mV}$ more positive than the anodic peak potential value. After the passage of $2 \mathrm{~F}$ for mol of reactive the electrolysis was stopped. Then, an oxidative reductive controlled potential at 
$0.00 \mathrm{~V}$ was carried out. The oxidation reduction process was monitorised by UVVIS absorption spectroscopy.

\section{Results and discussion}

Cyclic voltammetry of compound 10 at low scan rate shows one two-electron irreversible wave at 1.99 vs. SCE (Fig. 1). The high oxidation potential makes difficult to study the electrochemical oxidation mechanism of the compound, and consequently the nature of the chemical reaction coupled to the electron transfer.

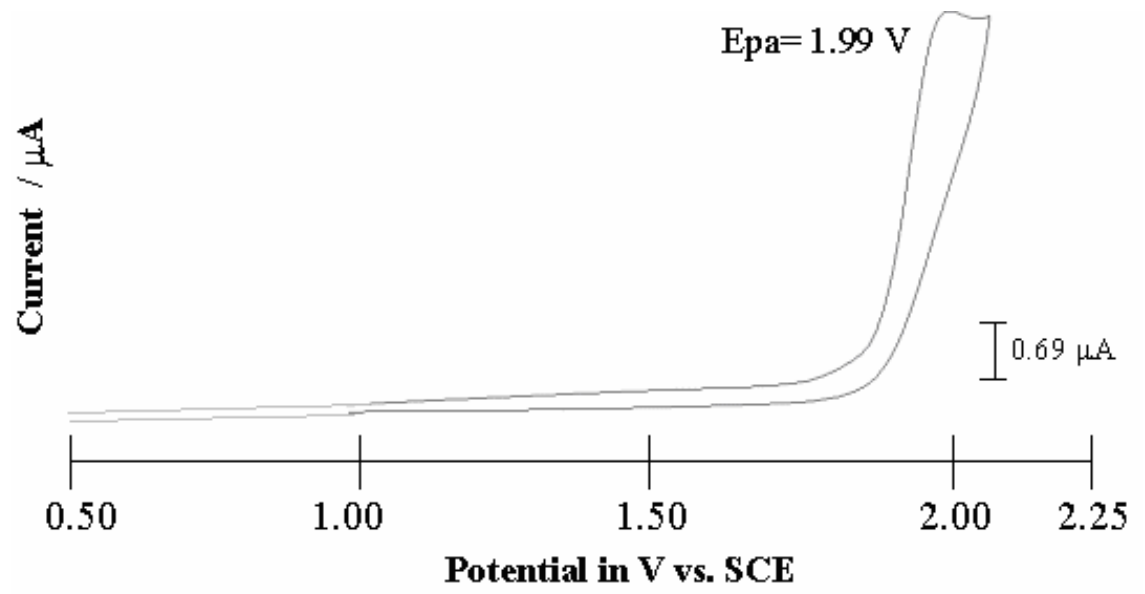

Figure 1. Cyclic voltammetry $\mathrm{CV}$ of $10(1.10 \mathrm{mM})$ in $\mathrm{ACN}-0.1 \mathrm{M} n-\mathrm{Bu}_{4} \mathrm{NPF}_{6}$ at 1 V.s ${ }^{-1}$. Scan range: $1.00 /+2.10 / 1.00 \mathrm{~V}$. Working electrode: glassy carbon electrode $(0.5$ mm diameter).

In order to solve this problem, the strongly electron withdrawing perfluorocyclopentene substituent was replaced by a cyclopentene (2o) substituent so as to shift the peak potential to a more accessible oxidation potential values (Fig. 2). Effectively, the potential oxidation value decreases by $600 \mathrm{mV}$ and the electrochemical oxidation mechanism does not seem to be modified. Like in the case of $\mathbf{1 0}$ a two-electron irreversible wave at $1.36 \mathrm{~V}$ is obtained for 2o. At this point, it is possible to determine the nature of the chemical reaction coupled to the electron transfer.

Due to the fact that the oxidation wave is irreversible over the whole range of accessible scan rates (until $50 \mathrm{~V} / \mathrm{s}$ ), another approach was used to elucidate the electrochemical oxidation mechanism. It consists in the observation of the peak potential, Epa, with the scan rate and the values of the half peak width, Ep/2-Ep. Thus, voltammetric data obtained for $\mathbf{2 0}$ under pure kinetic conditions indicate that an "EC" mechanism takes place, as shown by peak width analysis (Ep/2-Ep) $(48 \mathrm{mV})$, in which the electron transfer step is coupled to a chemical reaction. The variation of the peak potential value with the scan rate is $20 \mathrm{mV}$ per decade of scan rate at low scan rates (see Fig. 2) and the fact that peak potential value is concentration dependent (Fig. 3) indicates that chemical reaction linked to the electron transfer's kinetics is of second order $\left(\mathrm{EC}_{2}\right)$ [8]. Thin layer chromatography analysis of the result of a controlled potential electrolysis at 1.50 $\mathrm{V}$ on 20 shows that, after $2 \mathrm{~F}$, more polar photochromic compounds are produced. 
We can conclude that the initial radical cation of the open form undergoes a dimerization reaction, yielding to heavier compounds in which the photochromic core is not greatly affected despite further oxidation. Thus, chloro compounds $\mathbf{1 0}$ and 20 behave as most of the thiophene derivatives for which the early stages of oxidation involve radical cation dimerization (Scheme 3).

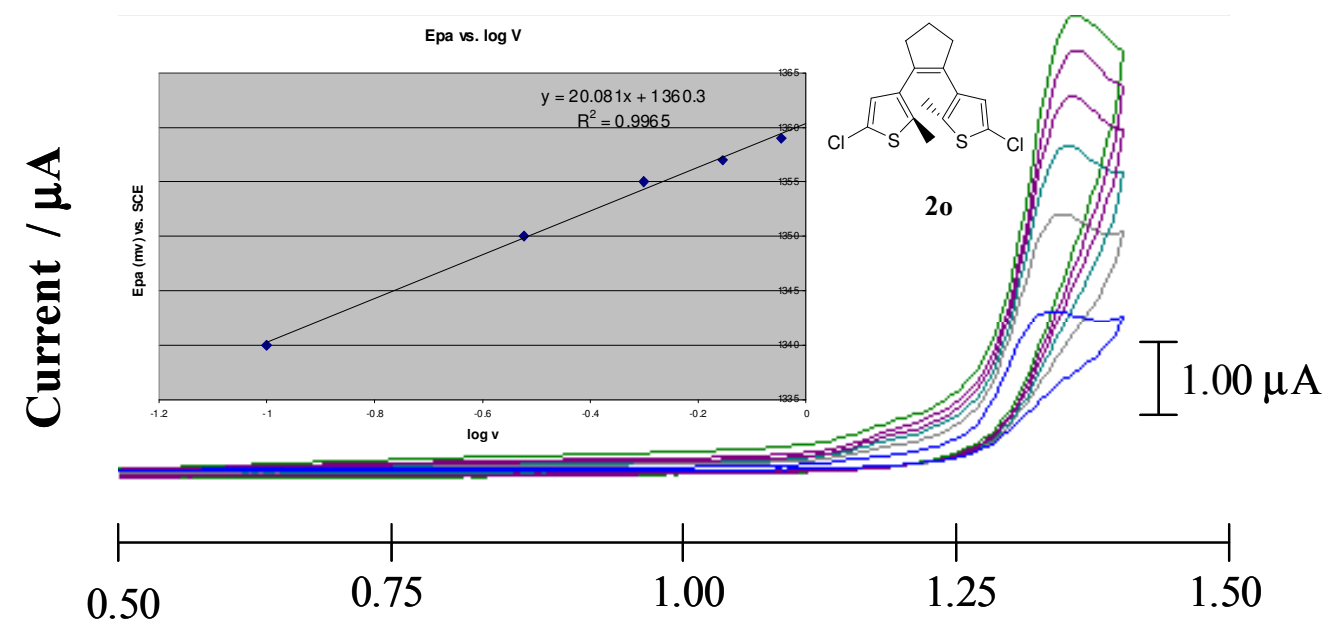

Potential in V vs. SCE

Figure 2. Cyclic voltammetry $\mathrm{CV}$ of $20(1.35 \mathrm{mM})$ in $\mathrm{ACN}-0.1 \mathrm{M} n-\mathrm{Bu}_{4} \mathrm{NPF}_{6}$ at

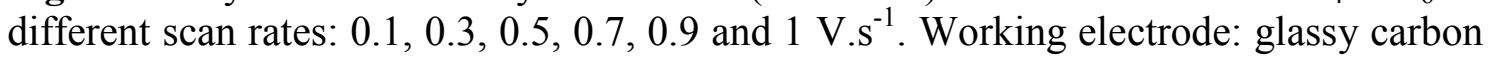
electrode $(0.5 \mathrm{~mm}$ diameter).
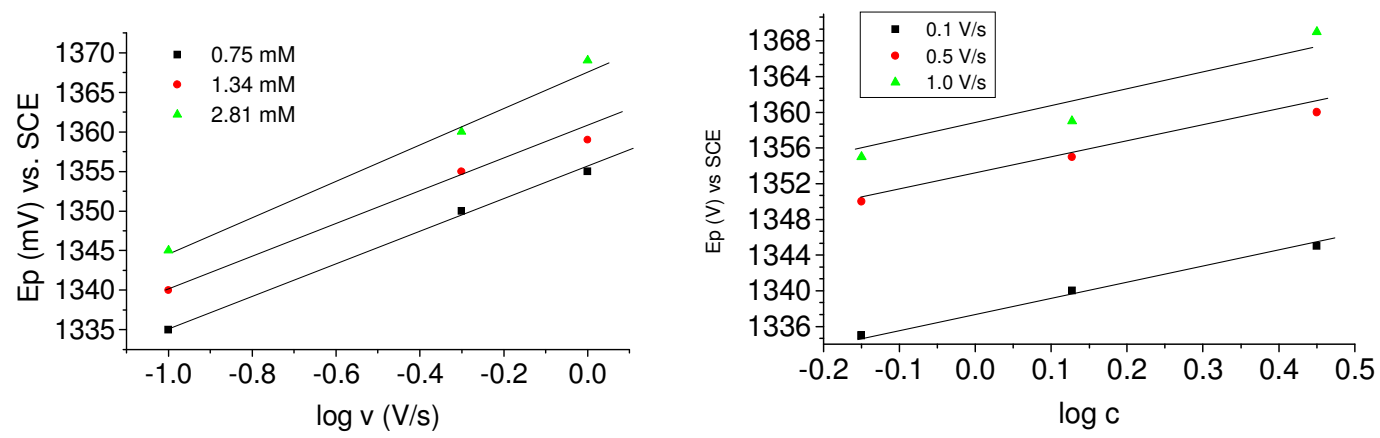

Figure 3. Variation of the peak potential for the oxidation of 20 in $\mathrm{ACN}+0.1 \mathrm{M} n$ $\mathrm{Bu}_{4} \mathrm{PF}_{6}$ at different scan rates and different concentrations. The solid lines represent the fitting of the experimental data.

The proposed mechanism for compounds $\mathbf{1 0}$ and $\mathbf{2 0}$ is shown in scheme 3 . 


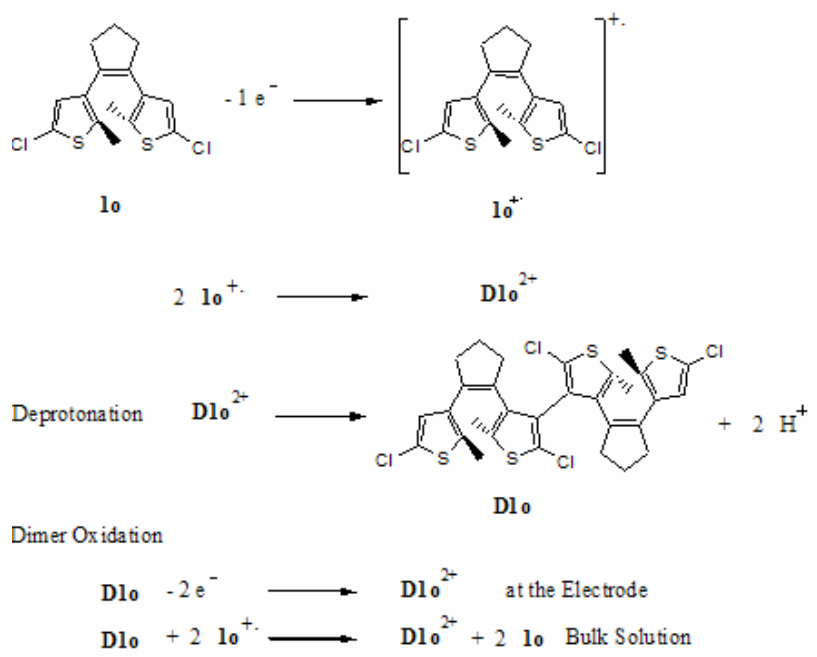

Scheme 3

In order to stabilize the initial radical cation formed upon electrochemical oxidation, the di(phenylthio) derivative 3o was synthesized. Cyclic voltammetry experiments show a two-electron irreversible wave, like in the case of compounds 10 and 20. However, careful investigations revealed a totally different electrochemical oxidation mechanism for compound $\mathbf{3 o}$.

The characteristic voltammogram $\left(1.00 \mathrm{~V} \mathrm{~s}^{-1}\right)$ of 30 in ACN is shown in Fig. 4a. The irreversible two-electron oxidation wave (ca. $1.20 \mathrm{~V}$ vs. SCE) on the first anodic scan, is followed by a reduction wave on the cathodic scan. The expected anodic counterpart is obtained on the second cycle giving a reversible wave centered on a redox potential value of $0.40 \mathrm{~V}$ vs. SCE. This $\mathrm{E}^{\circ}$ value corresponds to the standard oxidation potential of $\mathbf{3 c}$.

The oxidation wave is irreversible over the whole range of accessible scan rates (until $50 \mathrm{~V} / \mathrm{s}$ ), so as to elucidate the electrochemical oxidation mechanism the voltammetric data obtained are carefully analyzed. The peak potential value of $\mathbf{3 0}$ is not concentration dependent, and its variation with the scan rate is $34 \mathrm{mV}$ per decade of scan rate at low scan rates. We can, therefore, conclude that the initially produced radical cation reacts following a first order reaction pathway. The nature of the chemical reaction linked to the electron transfer is the ring closure reaction. Once cyclized the $\mathbf{3} \mathbf{c}^{++}$radical cation is oxidized again at this potential yielding the final stable dication $\mathbf{3} \mathbf{c}^{2+}$. Thus, two electron transfers separated by a chemical reaction are taking place, leading to a global ECE or DISP1 mechanistic.

The great stability of $\mathbf{3 c}^{\mathbf{2 +}}$ allows us to perform an exhaustive oxidative controlled potential electrolysis of a solution of $\mathbf{3 0}$ at $+1.25 \mathrm{~V}$ and solutions of the dication $3 \mathbf{c}^{2+}$ can then be prepared cleanly by this way $(2 \mathrm{~F})$. By switching down the potential to $0.00 \mathrm{~V}$ an exhaustive reduction takes place, and after the passage of $2 \mathrm{~F}$ the compound $\mathbf{3 c}$ is obtained in quantitative yield. Exposed to dimmed day light, solutions of 3c revert back to the colourless 3o. The two closed compound $\mathbf{3 c}$ (bright orange) and $\mathbf{3} \mathbf{c}^{\mathbf{2}}$ (dark orange) have very similar 
absorption spectra: both present an intense absorption band centered around 480 $\mathrm{nm}$. However, the closed compound $\mathbf{3 \mathbf { c } ^ { 2 + }}$ shows an intense band around $385 \mathrm{~nm}$ and a less intense one around $710 \mathrm{~nm}$, which is not present in the compound $\mathbf{3 c}$ (Fig. 5). According to the results presented above, the photoelectrochemical behaviour of compound $\mathbf{3}$ in $\mathrm{ACN}$ can be considered as a unique photoisomerization-electroisomerization three-states conjugated system.

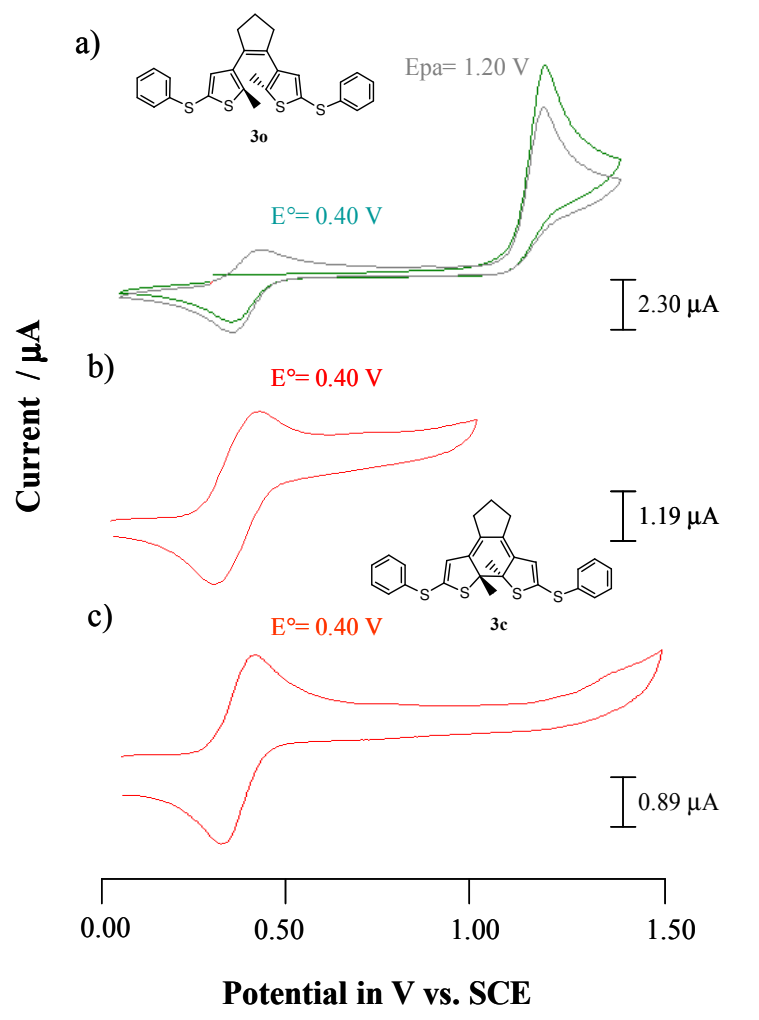

Figure 4. a) $\mathrm{CV}$ of $30(1.35 \mathrm{mM})$ in $\mathrm{ACN}-0.1 \mathrm{M} \mathrm{n}$-Bu4NPF6 $1.00 \mathrm{~V} \mathrm{~s}^{-1}$. Scan range: $1.00 / 0.00 /+1.50 / 0.00 \mathrm{~V}$ (two cycles). b) $\mathrm{CV}$ of $\mathbf{3 c}(0.45 \mathrm{mM})$. c) $\mathrm{CV}$ of a solution of $\mathbf{3 0}$ $(1.35 \mathrm{mM})$ in $\mathrm{ACN}-0.1 \mathrm{M}$-Bu4NPF6 electrolysed at $1.20 \mathrm{~V}(2 \mathrm{~F})$, and ensuing electrolysed at $0.00 \mathrm{~V}(2 \mathrm{~F})$. Scan range: $0.10 /+1.50 / 0.10 \mathrm{~V}$. Working electrode: glassy carbon electrode $(0.5 \mathrm{~mm}$ diameter $)$.

This conjugated system may lead to electrical-optical switching applications, using the combination of electro-photochromism properties in a single molecule unit. Thus, the system may be recognized as a dual-mode chemical signal transducer with distinctive color changes. In this sense we would like to design as well as explore related systems, which will show a dramatic change of colors between redox states. 


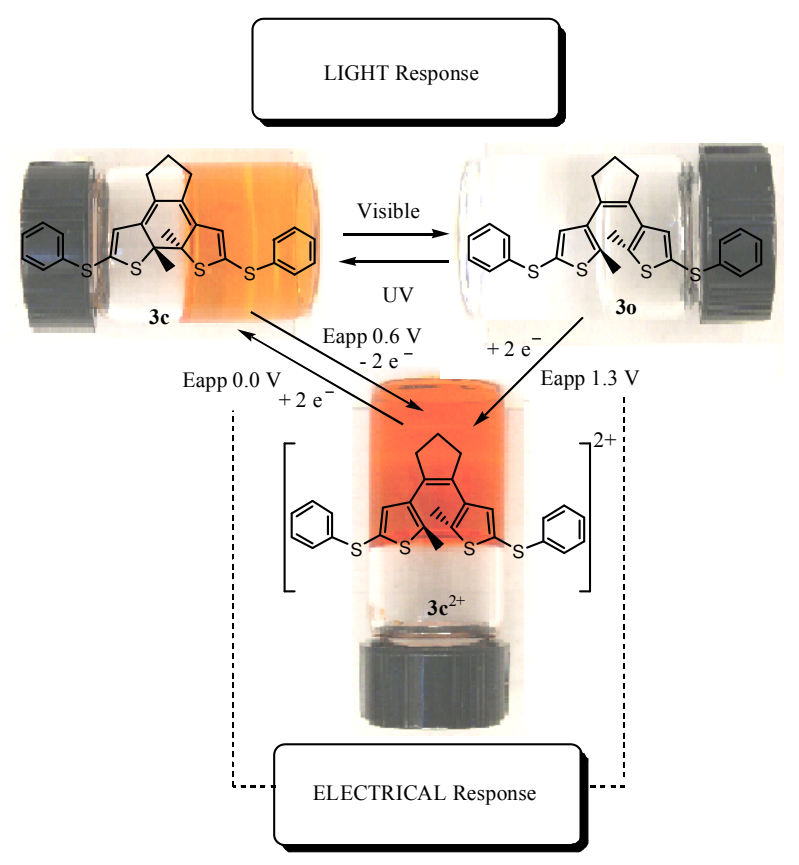

Figure 5. Photo-electrochemical system.

At this point there are still some questions remaining: in particular, when can occur the ring opening process triggered electrochemically? This question has a special importance because in the case of compound $\mathbf{3 c}$, as we above mentioned, no ring opening process is observed. Compound $\mathbf{3 c}$ shows a reversible pseudo two-electron oxidation wave $\left(\Delta \mathrm{E}^{\circ}=37 \mathrm{mV}\right)$ (Fig. $\left.4 \mathrm{~b}\right)$. In these sense similar results are obtained for compound 2c. At $0.67 \mathrm{~V}$ a reversible one-electron oxidation wave is found (Fig. 6a). Thus, the radical cation and the dication are stable intermediates even in the case of the dichlorodithienylclopentene derivative. In a general way the electrochemical behavior of these ring-closed isomers seems to remember the one showed for tetrathiafulvane derivatives because of the high stability of the radical cations, and even dications.
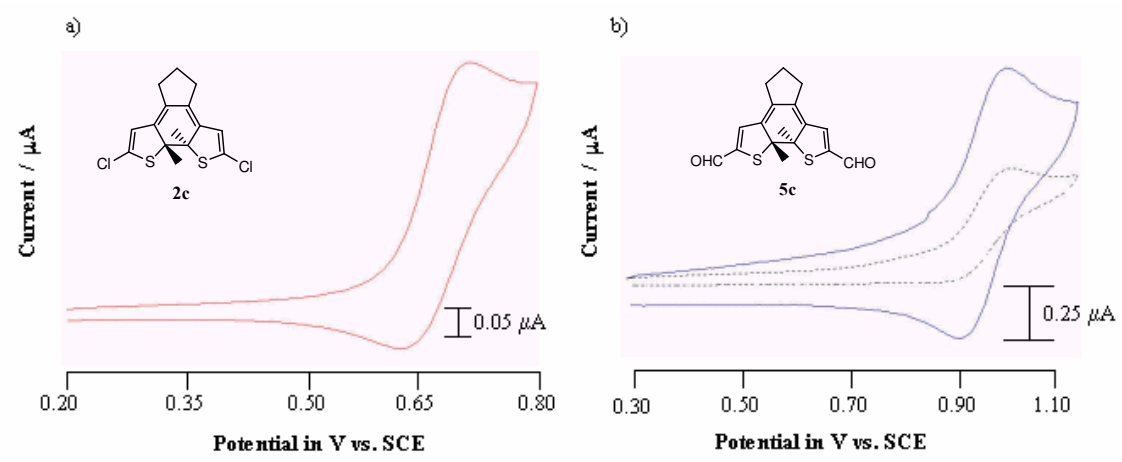

Figure 6. a) $\mathrm{CV}$ of $2 \mathbf{c}(0.20 \mathrm{mM})$ in $\mathrm{ACN}-0.1 \mathrm{M} \mathrm{n}-\mathrm{Bu} 4 \mathrm{NPF} 6$ at $0.1 \mathrm{~V}^{-1}{ }^{-1}$. b) $\mathrm{CV}$ of $\mathbf{5 c}$ $(0.50 \mathrm{mM})$ in ACN-0.1 M n-Bu4NPF6; dotted line: $0.4 \mathrm{~V} . \mathrm{s}^{-1}$; solid line: $2 \mathrm{~V} . \mathrm{s}^{-1}$. 
For testing the stability of the radical cation of dithienylcyclopentene ring closed isomers, we decide to study less favorable cases by introduction of strong electron withdrawing substituents in the molecule. For instance, the compound 5c, where two groups aldehyde are present in the molecule, will be a good candidate for this purpose. The characteristic voltammogram of $\mathbf{5 c}$ at low scan rates $\left(0.1-0.4{\left.\mathrm{~V} . \mathrm{s}^{-1}\right)}^{-1}\right.$ shows a one electron irreversible wave at $0.98 \mathrm{~V}$ (Fig. 6b). In order to elucidate the electrochemical oxidation mechanism of $\mathbf{5 c}^{+}$a study increasing the scan rate is performed. A fully reversible wave is obtained at 2 V.s ${ }^{-1}, \mathrm{E}^{\circ}=0.93 \mathrm{~V}$ vs. SCE (Fig. 7c) [8]. Controlled potential electrolysis at $1.2 \mathrm{~V}$ indicates that the original blue-purple color (characteristic of the closed isomer 5c, since the closed isomer presents a characteristic band at $580 \mathrm{~nm}$ ) was discharged in a few minutes, after the passage of $1 \mathrm{~F}$. The possibility of having an electrocatalytic ring opening mechanism was also tested using tris(4bromophenyl)amine hexachloroantimoniate as a chemical oxidant $\left(\mathrm{E}^{0}=1.10 \mathrm{~V}\right.$ s. $\mathrm{SCE}$ in $\mathrm{ACN}$ ); 0.4 equivalents of chemical oxidant are needed to fully oxidized the sample, which seems to indicate the catalytic character of the process. All the data obtained are consistent with a ring open isomerisation mechanism where the carbon-carbon bond cleavage seems to be the chemical reaction linked to the electron transfer (scheme 4).

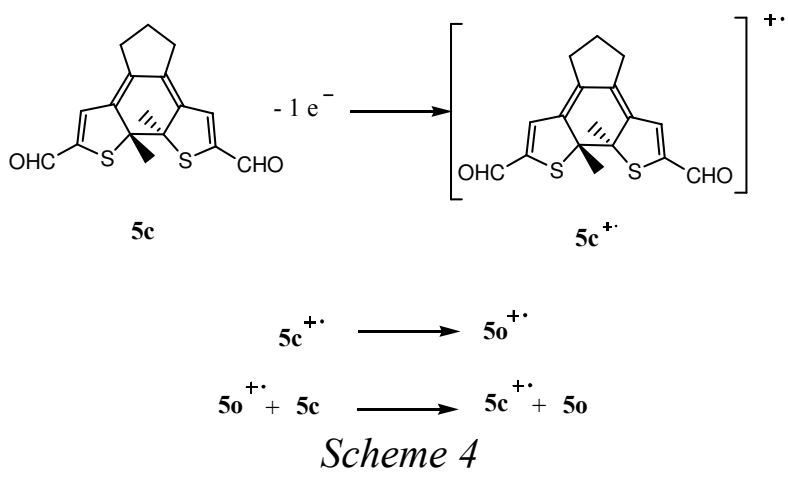

Due to the fact that the presence of electron withdrawing subtituents may favor ring opening processes, it would be desirable to know how the presence of the ring will affect the radical cation pathways. It seems that in some cases the presence of a perfluorocyclopentene ring in the core of the photochromic units not only will make them more difficult to oxidize, but also can modify the electrochromic properties. In the case of 1c a one-electron irreversible wave is obtained while in the case of $\mathbf{2 c}$, as above mentioned, a one-electron reversible wave is obtained. When controlled potential electrolysis a $1.4 \mathrm{~V}$ indicates the original red-pink color (characteristic of the closed isomer 1c, since the closed isomer presents a characteristic band at $508 \mathrm{~nm}$ ) was discharged in a few minutes, after the passage of $1 \mathrm{~F}$. Cyclic voltammetry, UV-Vis absorption spectroscopy, and thin layer chromatography analysis (TLC) of the resulting solution indicate that the ring-open isomer $\mathbf{1 0}$ is the only product obtained (Scheme 5). 


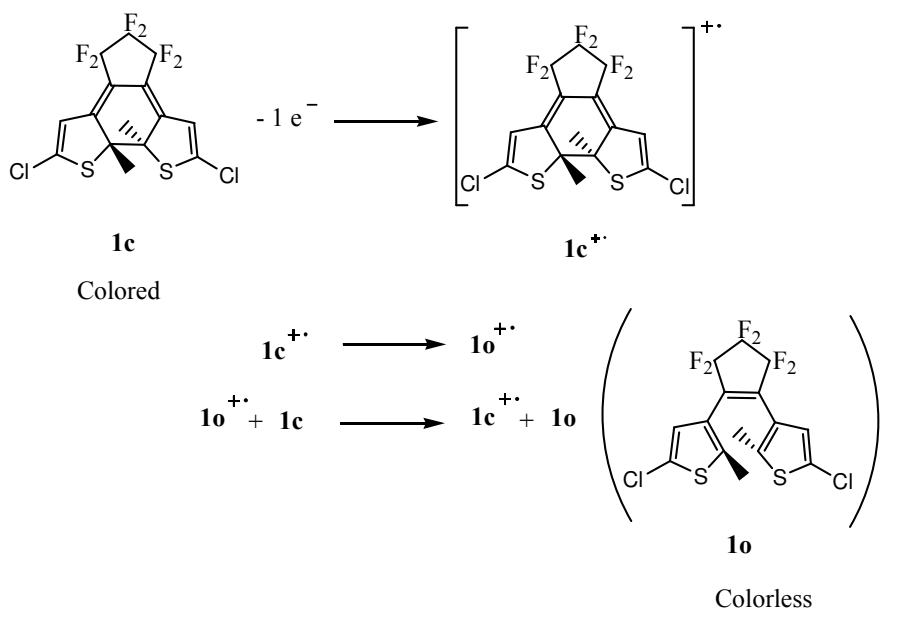

Scheme 5

It is remarkable that by using cyclic voltammetry as a mechanistic tool, it may be possible to determine the radical cation reaction pathway, and test the possible electrochromism of our diethienylcyclopentene molecular switches. Some additional photochromic systems were chosen so as to test if it is possible to predict the electrochromic behavior using cyclic voltammetry analysis. Compounds 4, 6, 7 and 8 (Scheme 6).

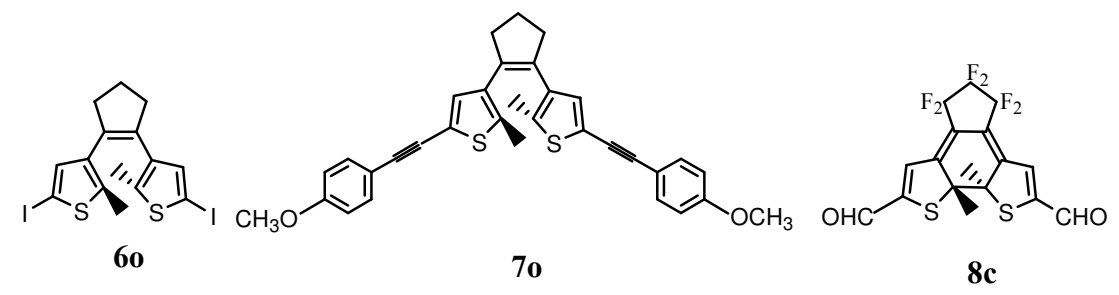

\section{Scheme 6}

Table 1 summarizes the mechanistic data collected for the above mentioned molecular switches. The data predict a dimerization mechanism for compound $\mathbf{6 o}$, a ring closure process for compound $\mathbf{7 0}$ as well as for compound $\mathbf{6 0}$, and ring opening for compound 8c. This prediction was confirmed by performing controlled potential electrolysis for compound $\mathbf{6 0}$; similar results as described above for compound 10 were obtained. The ring closure proposed for $\mathbf{4 0}$ and $\mathbf{8 0}$ were ratified by synthesizing photochemically the ring closed isomers (Fig. 7). 
Table 1. Voltammetric data for the oxidation of photochromic switches 4o, 5o, 60 and $7 \mathrm{c}$ in $\mathrm{ACN}$ at room temperature with $0.1 \mathrm{M} \mathrm{TBAPF}_{6}$ electrolyte by cyclic voltammetry using glassy carbon electrode.

\begin{tabular}{|c|c|c|c|c|}
\hline & \multicolumn{4}{|c|}{ Compound } \\
\hline & 40 & 60 & 70 & $8 \mathrm{c}$ \\
\hline $\begin{array}{l}\text { Ep vs. log v slope } \quad(\mathrm{mV} . \\
\left.\text { Decade }^{-1}\right)\end{array}$ & 30 & 19 & 30 & 30 \\
\hline $\begin{array}{l}\text { Ep vs. log c slope (mV. } \\
\left.\text { Decade }^{-1}\right)\end{array}$ & - & 19 & - & - \\
\hline $\mathrm{n}\left(\mathrm{F} \cdot \mathrm{mol}^{-1}\right)$ & 2 & 2 & 2 & 1 \\
\hline Predicted mechanism & ECE/DISP1 & $\mathrm{EC}_{2}$ & ECE/DISP1 & $\begin{array}{l}\text { EC } \\
\text { Stepwise }\end{array}$ \\
\hline Electrochromism & $\begin{array}{l}\text { YES } \\
\text { Ring } \\
\text { closure }\end{array}$ & $\begin{array}{l}\mathrm{NO} \\
\text { Dimerisation }\end{array}$ & $\begin{array}{l}\text { YES } \\
\text { Ring } \\
\text { closure }\end{array}$ & $\begin{array}{l}\text { YES } \\
\text { Ring } \\
\text { opening }\end{array}$ \\
\hline
\end{tabular}

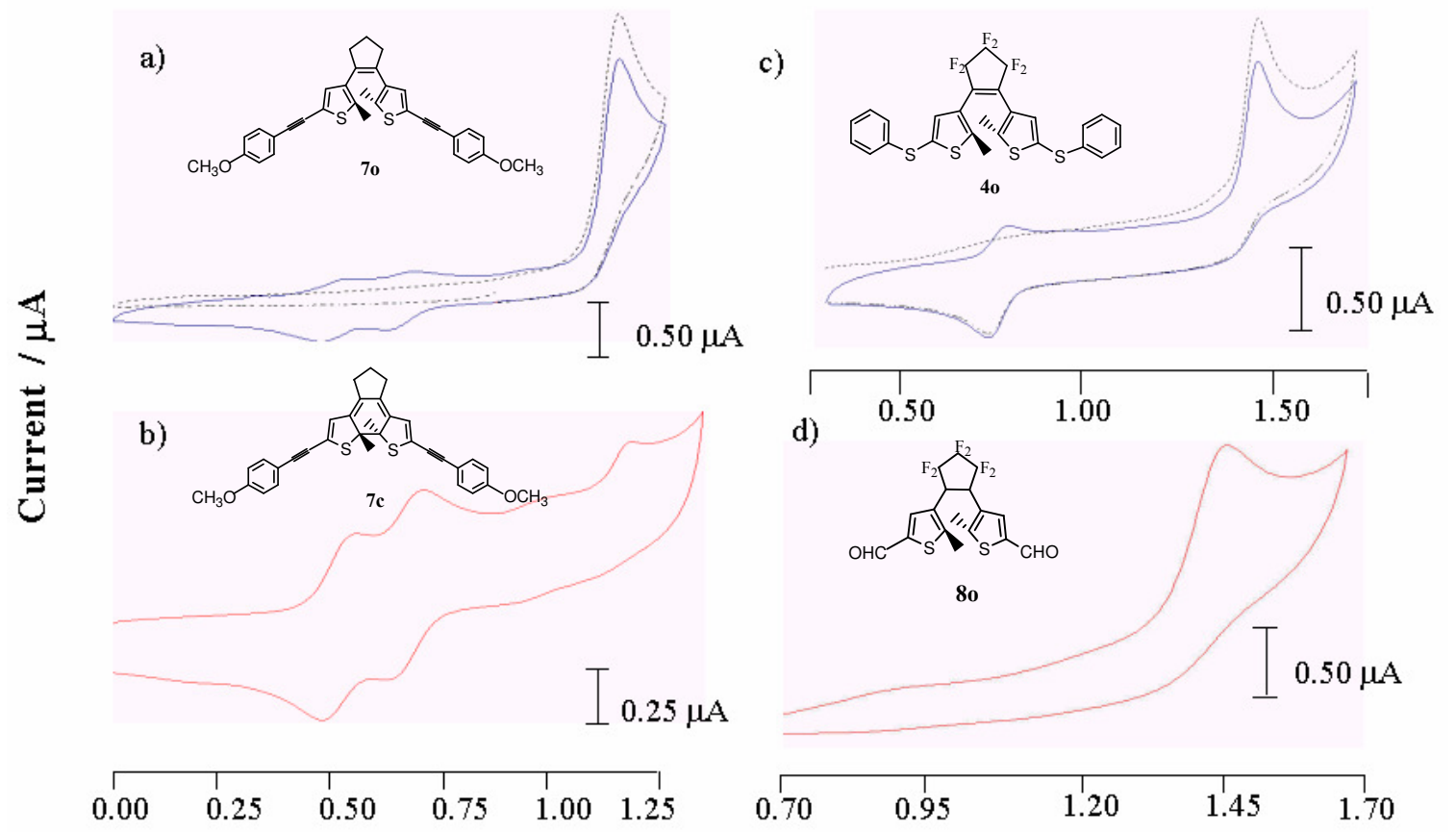

Potential in V vs. SCE

Figure 7. a) $\mathrm{CV}$ of $70(1.53 \mathrm{mM})$ in $\mathrm{ACN}-0.1 \mathrm{M} n-\mathrm{Bu}_{4} \mathrm{NPF}_{6}$ at $1.00 \mathrm{~V} \mathrm{~s}^{-1}$. (two cycles). b) $\mathrm{CV}$ of photolysed sample of $70(0.76 \mathrm{mM})$ at $1.00 \mathrm{~V} \mathrm{~s}^{-1}$. c) $\mathrm{CV}$ of a solution of $40(1.45 \mathrm{mM})$ in $\mathrm{ACN}-0.1 \mathrm{M} n-\mathrm{Bu}_{4} \mathrm{NPF}_{6}$ at $1.00 \mathrm{~V} \mathrm{~s}^{-1}$. d) CV of a solution of $80(0.73 \mathrm{mM})$ in $\mathrm{ACN}-0.1 \mathrm{M} n-\mathrm{Bu}_{4} \mathrm{NPF}_{6}$ at $1.00 \mathrm{~V} \mathrm{~s}^{-1}$. Working electrode: glassy carbon electrode (0.5 mm diameter). 
Controlled potential electrolysis at $1.8 \mathrm{~V}$ vs. SCE of a solution in ACN of ring closed isomer $\mathbf{8 c}$ after the passage of $1 \mathrm{~F}$ leads to the open isomer as the mechanistic study predicts and in contrast to a recent study published in the literature [6h]. The contradiction might be due to the potential applied in the above mentioned publication, which could have been too low for oxidizing the closed isomer $(1.5 \mathrm{~V}$ vs. $\mathrm{Ag} / \mathrm{AgCl})$. Compound $8 \mathrm{c}$ is very difficult to oxidize due to the presence of the perfluorocyclopentene ring and of the acceptor aldehyde substituents (Fig. 7d).

\section{Conclusions}

We have thus shown that photochromic dithienylethenes chromophores do undergo an irreversible oxidation at rather low potentials. Remarkably, the fate of the generated radical cations depends strongly on the substituent as clearly demonstrated by electrochemistry. With the notable exception of the halogenated (perhydro compounds) that show a "thiophene-like" electrochemical behaviour such as a radical-cation dimerisation, the ring closure is observed for all opened isomers with electrodonating groups that enhance the "triene-like" reactivity leading to a quantitative ring closure could be studied. Since this represents only the "most easy to oxidize", compounds were characterized by at least two electron donor substituents. On the other hand the ring-closed compounds fall into two electrochemical domains: below $0.8 \mathrm{~V}$, oxidations are electrochemically reversible and the generated charged species is usually stable. This necessitates the presence of electron donating groups such as a hydrogenated side chain and for instance thioether substituents. Above $0.8 \mathrm{~V}$, the oxidation is quasi reversible to irreversible and leads to the ring opening via a stepwise mechanism. Better oxidizer than the starting material, the resulting "open" cation-radical is quickly reduced to the neutral ring-open compound. This thus requires electron withdrawing substituents such as a perfluorinated side chain. Such a difference could be used to design new molecular devices combining electron transport and chemical reactions. Work is in progress in this direction.

\section{Acknowledgments}

We gratefully acknowledge the financial support of the Ministerio de Tecnologia y Ciencia of Spain through projects BQU 2003-05457 and CTQ2006-01040 and Mrs C. Viala (CEMES-CNRS) for recording the NMR spectra.

\section{References}

1. (a) T.R. Kelly, H.D. Silva and R.A. Silva, Nature 401 (1999) 150; (b) N. Koumura, R.W.J. Zijlstra, R.A. van Delden, N. Harada and B.L. Feringa, Nature 401 (1999) 152; (c) D.A. Leigh, J.K.Y. Wong, F. Dehez and F. Zerbetto, Nature 424 (2003) 174; (d) V. Balzani, M. Clemente-León, A. Credi, B. Ferrer, M. Venturi, A.H. Flood and J.F. Stoddart, Proc. Natl. Acad. Sci. USA 103 (2006) 1178. 
2. (a) K. Uchida, M. Saito, A. Murakami, S. Nakamura, M. Irie, Chem. Phys. Chem. 4 (2003) 11124; (b) K. Uchida, M. Saito, A. Murakami, S. Nakamura, M. Irie, Adv. Mat. 15 (2003) 121.

3. For an overview of electrochromism and its applications, see: (a) P.M.S. Monk, R.J. Mortimer, D.R. Rosseinky, Electrochromism: Fundamentals and Applications, VCH, New York, 1995; (b) C. Bechinger, S. Ferrere, A. Zaban, J. Sprague, B.A. Gregg, Nature 383 (1996) 608.

4. (a) M. Irie, Chem. Rev. 100 (2000) 1685; (b) H. Tian, S. Yang, Chem. Soc. Rev. 33 (2004) 85.

5. (a) T. Peglow, S. Blechert, E. Steckhan, Chem. Eur. J. 4 (1998) 107, and references therein; (b) K. Chiba, T. Miura, S. Kim, Y. Kitano, M. Tada, J. Am. Chem. Soc. 123 (2001) 11314.

6. (a) G. Guirado, C. Coudret, J.-P. Launay, J. Phys. Chem. C. (2007), in press; (b) G. Guirado, C. Coudret, J.-P. Launay, J. Phys. Chem. B. 109 (2005) 37, 1744; (c) C. Coudret, G. Guirado, C. Hortholary, J.-P. Launay, N. Battaglini, H. Klein and P. Dumas, Mol. Cryst. Liq. Cryst. 431 (2005) 501 ; (d) S. Fraysse, C. Coudret, J.-P. Launay, Eur. J. Inorg. Chem. (2000) 1581; (e) B. Gorodetsky, H.D. Samachetty, R.L. Donkers, M.S. Workentin, Angew. Chem. Int. Ed. 43 (2004) 2812; (f) A. Peters, N.R. Branda, J. Am. Chem. Soc. 125 (2003) 3404; (g) A. Peters, N.R. Branda, Chem. Commun. (2003) 954; (h) X.H. Zhou, F.S. Zhang, P.Yuang, F. Sun, S.Z. Pu, F.Q. Zhao, C.H. Tung, Chemistry Letters 33 (2004) 1006.

7. (a) L.N. Lucas, J.J.D de Jong, J.H.van Esch, R.M.Kellogg, B.L. Feringa, Eur. J. Org. Chem. (2003) 155; (b) L.N. Lucas, J.H. van Esch, R.M. Kellogg, B.L. Feringa, Chem. Comm. (1998) 2313.

8. (a) L. Nadjo, J.-M. Savéant, J. Electroanal. Chem. 48 (1973) 113; (b) C.P. Andrieux, J.-M. Savéant, Electrochemical Reactions, in Investigation of Rates and Mechanism of Reactions, Techniques of Chemistry, (Ed: C. F. Bernasconi) Wiley, New York (1986), vol. 6, ch. 2.1, p. 305. 